\title{
Theranostic Self-Assembly Structure of Gold Nanoparticles for NIR Photothermal Therapy and $X$-Ray Computed Tomography Imaging
}

\author{
Heng Deng ${ }^{1,2}$, Yanqi Zhong ${ }^{1,2}$, Meihong Du ${ }^{3}$, Qinjun Liu ${ }^{3}$, Zhanming Fan ${ }^{4}$, Fengying Dai ${ }^{1,}$, , and \\ Xin Zhang1, \\ 1. National Key Laboratory of Biochemical Engineering, Institute of Process Engineering, Chinese Academy of Sciences, Beijing, 100190, \\ China. \\ 2. University of Chinese Academy of Sciences, No. 19A Yuquan Road, Beijing, 100049, China. \\ 3. Beijing Center for Physical and Chemical Analysis, Beijing, 100089, China. \\ 4. Department of Radioloy, Beijing Anzhen Hospital, Capital University, No. 2 Anzhen Road, Chaoyang District, Beijing, China.
}

$\triangle$ Corresponding authors: Xin Zhang, Professor, PhD, Fax: +86-010-82544853 Email: xzhang@home.ipe.ac.cn; Zhanming Fan, PhD, Fax: +86-010-64456310 Email: fanzm120@126.com; Fengying Dai, PhD, Fax: +86-010-82544990 Email: fydai@home.ipe.ac.cn.

() Ivyspring International Publisher. This is an open-access article distributed under the terms of the Creative Commons License (http://creativecommons.org/ licenses/by-nc-nd/3.0/). Reproduction is permitted for personal, noncommercial use, provided that the article is in whole, unmodified, and properly cited.

Received: 2014.04.20; Accepted: 2014.05.27; Published: 2014.07.0I

\begin{abstract}
The controllable self-assembly of amphiphilic mixed polymers grafted gold nanoparitcles (AuNPs) leads to strong interparticle plasmonic coupling, which can be tuned to the near-infrared (NIR) region for enhanced photothermal therapy (PTT). In this study, an improved thiolation method was adopted for ATRP and ROP polymer to obtain amphiphilic brushes of PMEO $\mathrm{O}_{2} \mathrm{MA}-\mathrm{SH}$ and PCL-SH. By anchoring PCL-SH and PMEO ${ }_{2} M A-S H$ onto the $14 \mathrm{~nm}$ AuNPs, a smart hybrid building block for self-assembly was obtained. Increasing the $\mathrm{PCL} / \mathrm{PMEO}_{2} \mathrm{MA}$ chain ratio from 0.8:I, $2: \mathrm{I}$ and 3:I to 7:I, the structure of gold assemblies (GAs) was observed to transfer from vesicle to large compound micelle (LCM). Contributed to the special dense packed structure of gold nanoparticles in LCM, the absorption spectrometry of gold nanoparticles drastically red-shifted from $520 \mathrm{~nm}$ to $830 \mathrm{~nm}$, which endowed the GAs remarkable NIR photothermal conversion ability. In addition, gold has high X-ray absorption coefficient which qualifies gold nanomaterial a potential CT contrast agent Herein, we obtain a novel gold assembly structure which can be utilized as potential photothermal therapeutic and CT contrast agents. In vitro and In vivo studies testified the excellent treatment efficacy of optimum GAs as a PTT and CT contrast agent. In vitro degradation test, MTT assay and histology study indicated that GAs was a safe, low toxic reagent with good biodegradability. Therefore, the optimum GAs with strong NIR absorption and high X-ray absorption coefficient could be used as a theranostic agent and the formation of novel gold large compound micelle might offers a new theory foundation for engineering design and synthesis of polymer grafted AuNPs for biomedical applications.
\end{abstract}

Key words: Photothermal therapy, polymer grafted gold nanoparticles, theranostics, near-infrared absorption, large compound micelles

\section{Introduction}

Photothermal therapy (PTT), which utilizes photothermal conversion reagents to generate heat energy from absorbed light to achieve effective treatment for various malignant diseases, has been increasingly recognized in cancer treatment [1-4]. In order to avoid unnecessary photodamage to organ- 
isms, near-infrared (NIR) laser is selected as the optimum light source in clinical therapy, as NIR laser features high penetrability to skin which results in less damage [5-7]. The gold nanomaterials such as gold nanorods, hollow gold shells, nanocages, nanostar and nanoflowers, which can absorb NIR light tremendously and convert it into heat energy efficiently, have been widely explored for PTT [2, 8-12]. Compared to traditional origanic dyes, these gold nanomaterials stand out for their excellent properties of high photo-stability and light-thermal conversion efficiency [13-15]. Other than that, gold has a higher X-ray absorption, which makes these gold nanomaterials a potential CT imaging contrast agent $[16,17]$. Possessing the functions of PTT and CT imaging at the same time, gold nanomaterials could be a possible theranostics agent which combines diagnosis modalities and therapy applications [18, 19]. However, these gold nanomaterials are inevitably with a dimension bigger than $40 \mathrm{~nm}$ which is adverse to body clearance efficiency [20].

Compared to the aforementioned gold nanomaterials with peculiar structures, the smaller spherical AuNPs is not suitable for PTT because of its poor ability to absorb NIR light. Nevertheless, induced aggregation of spherical AuNPs can be a perfect match for this situation due to the localized surface plasmon resonance (LSPR) between adjacent gold nanoparticles, thereby opening a wealth of possibilities to tune these gold nanocrystals into strong NIR photoabsorber [21, 22]. For example, Zhong and co-workers used multidentate thioethers to induce AuNPs self-assembling into superstructure with absorption at longer wavelength [23, 24]. But such gold assembly is still not suitable for PTT, because the aggregation of these AuNPs is not easy to disintegrate into small discrete AuNPs. Even though it shows an excellent ability to kill the cancer cells, the aggregation with large size of hundreds nanometers cannot be cleared out from organisms.

To resolve the problem mentioned above, novel reversible superstructure composed by small spherical AuNPs is desirable. In the state of aggregation it shows an enhanced photothermal effect, after the PTT this superstructure can be broken down into dissociated AuNPs, which benefits the clearance of AuNPs. Supramolecular chemistry may be a powerful tool to obtain such reversible self-assembly superstructure, which offer a weak force to bind up discrete AuNPs together [25]. Recently, two groups of Nie and Duan had respectively offered workable ways for constructing spherical AuNPs into superstructure, which can be disintegrated into discrete particles. They use amphiphilic polymer to modify trisodium citrate coated AuNPs with size from $14 \mathrm{~nm}$ to $40 \mathrm{~nm}$. These smart AuNPs inherit the self-assembly ability of amphiphilic polymers as well as the capability to form vesicular structures which tune the light absorptions of AuNPs at longer wavelength. Compared to small clusters of gold NPs such as gold nanochain, these smart structures could also be used as light-sensitive carrier for drug control release [26]. In particular, Nie used PS-PEG block polymer grafted $40 \mathrm{~nm}$ AuNPs [27] and PCL-PEG block polymer grafted $26 \mathrm{~nm}$ AuNPs [25] as building block respectively to obtain gold superstructure which showed a SPR peak at NIR region. However when smaller $14 \mathrm{~nm}$ AuNPs are used as building block, the LSPR red-shift of this gold superstructure was not so ideal [27, 28]. For example, Duan used PMMAVP /PEG mixed grafted $14 \mathrm{~nm}$ AuNPs as building block only obtaining gold vesicle with a SPR peak at $546 \mathrm{~nm}$ [28]. It is obviously that the smaller AuNPs being used as building block, the more challenging the work that tune them into strong NIR photoabsorber would be [27, 29]. To enhance the performance of the composites, it is critical to control the spatial arrangement of individual gold nanoparticles within the polymer hosts with high precision.

Encouraged by the pioneering works aforementioned, we used $14 \mathrm{~nm}$ AuNPs as building blocks for self-assembly. Biodegradable hydrophobic poly ( $\varepsilon$-caprolactone) (PCL) and hydrophilic poly 2-(2-methoxyethoxy) ethyl methacrylate $\left(\mathrm{PMEO}_{2} \mathrm{MA}\right)$ were used to offer amphiphilic-driven force for inducing self-assembly of these AuNPs. It should be noted that this smart AuNPs modified by chemically distinct polymer brushes was analogous to block copolymers as a whole. And it is well-known that block copolymers can self-assembly into a variety of microstructures when the hydrophobic/hydrophilic ratio changes [30-33]. Theoretically, the plasmonic coupling of neighbour AuNPs performs differently in diverse ordered structure aggregations via polymer self-assembly. In our work, the optimal red-shift of LSPR band was expected to obtain by the design of hydrophobic and hydrophilic chain ratio grafting onto the surface of AuNPs as shown in Scheme 1. In this way a gold assembly with strong NIR absorption and X-ray absorption will be obtained. The effect of PTT and CT imaging were evaluated in cell level and tumor-bearing mice. This new structure assembled from small $14 \mathrm{~nm}$ AuNPs would play a significant role in promoting the use of gold assembly as photosentitizers and CT contrast agent in tumor therapy and diagnose. 


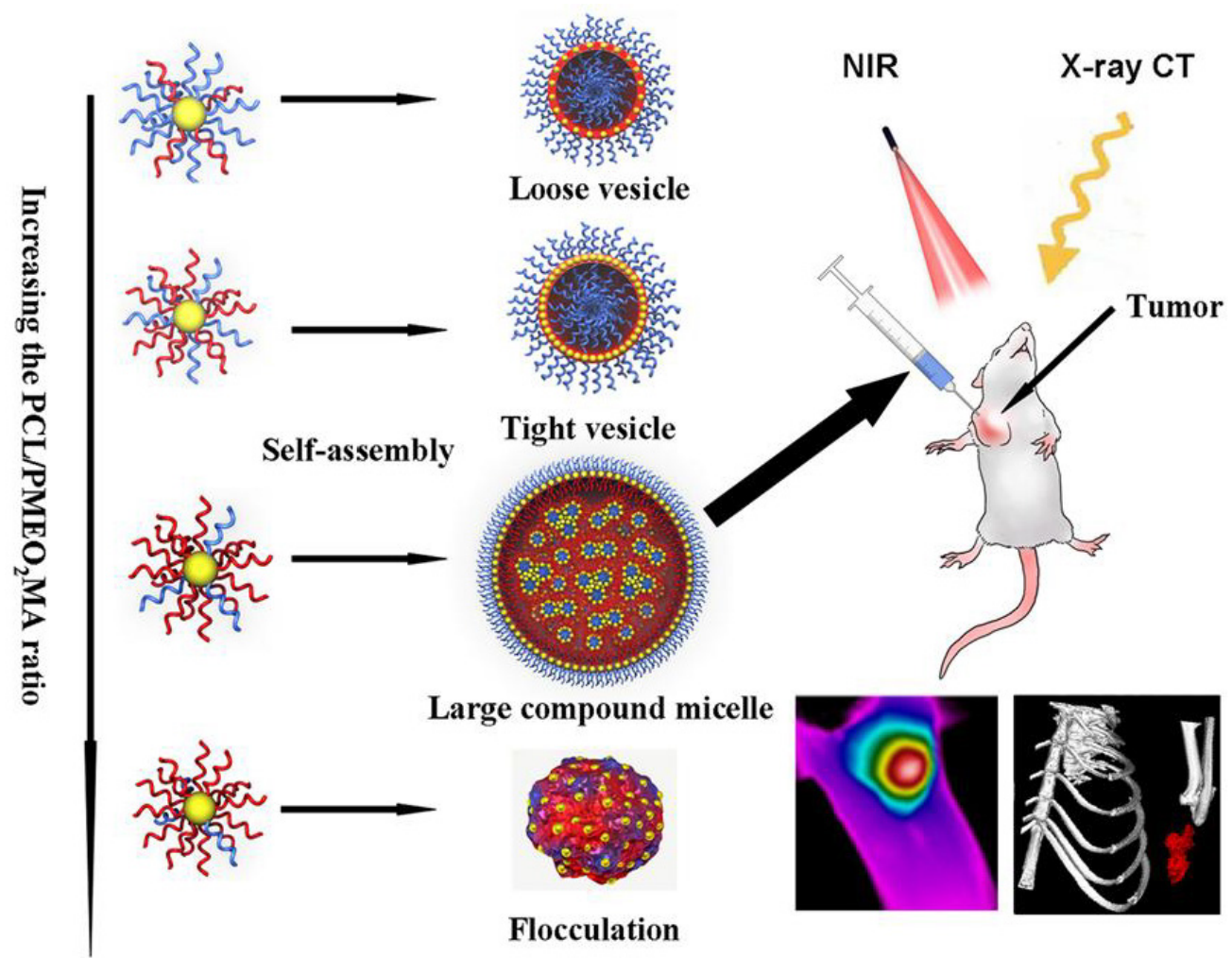

Scheme I. Schematic representation of assemblies composed by PCL/PMEO 2 MA grafted AuNPs and their potential application in photothermal therapy and $\mathrm{CT}$ imaging of cancer.

\section{Materials and methods}

\section{Materials}

2-Hydroxyethyl 2'-methyl-2'-bromopro-pionate (HMB) was purchased from Changzhou Yipin Tang Chemical Co. LTD. Chloroauric acid $\left(\mathrm{HAuCl}_{4}\right), \mathrm{Sn}$ (Oct) 2 , $\varepsilon$-caprolactone ( $\varepsilon-\mathrm{CL}$ ) and 2-(2-methoxyethoxy) ethyl methacrylate $\left(\mathrm{MEO}_{2} \mathrm{MA}\right)$ were purchased from Aladdin reagent (Shanghai, China). Calcein-AM, propidium iodide (PI), esterase, methyl thiazolyl tetrazolium (MTT), copper bromide $(\mathrm{CuBr})$ and $N, N$, $N^{\prime}, N^{\prime}, \quad N^{\prime \prime}$-pentamethyldiethylenetriamine (PMDETA) were purchased from Sigma-Aldrich (St. Louis, Missouri).

\section{Synthesis of $\mathrm{PMEO}_{2} \mathrm{MA}-\mathrm{Br}$}

$\mathrm{PMEO}_{2} \mathrm{MA}$ was prepared via atom transfer radical polymerization (ATRP) method. In a typical procedure, copper bromide $(28.7 \mathrm{mg}, 0.2 \mathrm{mmol})$, monomer $\mathrm{MEO}_{2} \mathrm{MA}(1.88 \mathrm{~g}, 10 \mathrm{mmol})$, initiator HMB (42.4 $\mathrm{mg}, 0.2 \mathrm{mmol})$ and ethanol $(5 \mathrm{~mL})$ were added to a Schlenk tube sealed with a septum. After that, the tube was purged by dry nitrogen for half an hour. Then, degassed PMDETA (42 $\mu \mathrm{L}, 0.2 \mathrm{mmol})$ was added using a degassed syringe. Finally the mixture was heated at $60{ }^{\circ} \mathrm{C}$ in an oil bath under magnetic stirring for $12 \mathrm{~h}$. The experiment was terminated by opening the flask and exposing the catalyst to air. The final mixture was diluted in ethanol and passed through an alumina column to remove the catalyst. Following that, the filtered solution was diluted with deionized water and subsequently purified by dialysis in water (molecular weight cut-off: $3500 \mathrm{KD}$ ). As an end, water was removed by lyophilization.

\section{Synthesis of PCL-Br}

PCL-Br was prepared by ring-opening polymerization. In brief, a mixture of $\varepsilon$-caprolactone $(10.00 \mathrm{~g}, 87.7 \mathrm{mmol}), \mathrm{Sn}(\mathrm{Oct})_{2}(0.062 \mathrm{~g}, 0.153 \mathrm{mmol})$, HMB $(0.059 \mathrm{~g}, 0.277 \mathrm{mmol})$, and toluene $(15 \mathrm{~mL})$ were added to a round-bottom flask with a condenser and $\mathrm{CaCl}_{2}$ drying tube. The mixture was maintained at 110 ${ }^{\circ} \mathrm{C}$ under strong stirring for $12 \mathrm{~h}$. Then the reaction was stopped, and the mixture was precipitated from cold methanol. The precipitate was collected by filtration and dried in a desiccator to yield PCL-Br.

\section{Transformation of polymer-Br into polymer-SH}

The bromine end-functionalized polymer ( $\mathrm{PMEO}_{2} \mathrm{MA}-\mathrm{Br}$ or $\mathrm{PCL}-\mathrm{Br}, 1$ equiv) and potassium thioacetate ( 3 equiv) were stirred in acetone and refluxed for $4 \mathrm{~h}$. Then, the acetone was removed, and the crude product was redissolved in dichloromethane, washed with water, and dried with sodium sulfate. The resulting pale-yellow thio-ester 
end-functionalized polymer was obtained. Then the thio-ester end-functionalized polymer $(500 \mathrm{mg})$, hydrazine hydrate $(500 \mu \mathrm{L})$ and $\mathrm{CH}_{3} \mathrm{CN}(5 \mathrm{~mL})$ were added to a round-bottom flask and reaction was continued for $90 \mathrm{~min}$ under $25^{\circ} \mathrm{C}$. The reaction mixture was diluted with chloroform and sequentially washed with $1 \mathrm{~mol} / \mathrm{L}$ aqueous $\mathrm{HCl}$, saturated aqueous $\mathrm{Na}-$ $\mathrm{HCO}_{3}$, and saturated aqueous $\mathrm{NaCl}$. The organic phase was dried over anhydrous $\mathrm{Na}_{2} \mathrm{SO}_{4}$ and concentrated under reduced pressure to afford the polymer-SH.

\section{Synthesis of I4nm AuNPs}

$10 \mathrm{mg}$ of $\mathrm{HAuCl}_{4}$ was dissolved in $100 \mathrm{~mL}$ of $\mathrm{H}_{2} \mathrm{O}$ and heated to boiling under stirring. $3 \mathrm{~mL}$ of sodium citrate ( $1 \mathrm{wt} \%)$ solution was then quickly injected. The reaction mixture was refluxed for 30 min. AuNPs were collected by centrifuging the above solution at $11000 \mathrm{rpm}$.

\section{Synthesis and self-assembly of amphiphilic AuNPs.}

Amphiphilic AuNPs were synthesized by grafting $\mathrm{PMEO}_{2} \mathrm{MA}-\mathrm{SH}$ and PCL-SH onto AuNPs. For example, mixture of thiol-ended $\mathrm{PMEO}_{2} \mathrm{MA}(50 \mathrm{mg})$ and PCL $(50 \mathrm{mg})$ was first dissolved in $10 \mathrm{~mL}$ of DMF/THF $(1: 1, \mathrm{vol})$. Then, a concentrated solution of AuNPs $(4 \mathrm{mg} / \mathrm{mL})$ was slowly added into the above solution under vigorous magnetic stirring. Subsequently, the mixture was sonicated for 1 hour to avoid the aggregation of AuNPs. The solution was then steadily kept for overnight to finish the ligand exchange. The polymer modified AuNPs were further purified by centrifugation for 6-8 times and redispersion in THF. By adjusting the mass ratio of PCL and $\mathrm{PMEO}_{2} \mathrm{MA}$ from 2:8, 3:7, 4:6, 6:4 and to 8:2, a series of amphiphilic AuNPs with different ratio of PCL and $\mathrm{PMEO}_{2} \mathrm{MA}$ brushes were obtained. The self-assembly of amphiphilic AuNPs was triggered by slowly adding water into $1 \mathrm{~mL}$ THF solution of amphiphilic AuNPs $(4 \mathrm{mg} / \mathrm{mL})$ until the water content reached a targeted concentration ( $35 \mathrm{vt} \%$ ) within $2 \mathrm{~h}$. Then 10 $\mathrm{mL}$ water was added to the mixed solution quickly and the mixture was dialyzed (dialysis bags with the Mw cutoff of $3500 \mathrm{~g} / \mathrm{mol}$ ) against water to remove the residual THF for $24 \mathrm{~h}$.

\section{Calculation of the ratio of $\mathrm{PCL}$ and $\mathrm{PMEO}_{2} \mathrm{MA}$ grafts on the AuNPs surface}

${ }^{1} \mathrm{H}-\mathrm{NMR}$ measurement showed the resonance of $-\mathrm{CH}_{2} \mathrm{CO}-(2.4 \mathrm{ppm})$ of PCL and that of $-\mathrm{CH}_{2} \mathrm{OCH}_{2} \mathrm{CH}_{2} \mathrm{O}$ - (3.5-3.7 ppm) of $\mathrm{PMEO}_{2} \mathrm{MA}$, which led to a molar ratio for $\mathrm{CL}$ and $\mathrm{MEO}_{2} \mathrm{MA}$ monomer. With the molecular weights of $\mathrm{PMEO}_{2} \mathrm{MA}(10 \mathrm{kDa})$ and PCL $(27 \mathrm{kDa})$, the ratio of PCL and $\mathrm{PMEO}_{2} \mathrm{MA}$ grafts can be calculated using Equation S1, where $\mathrm{M}_{\mathrm{MEO} 2 \mathrm{MA}}$ is the molecular weight of $\mathrm{MEO}_{2} \mathrm{MA}$ monomer and $\mathrm{M}_{\mathrm{CL}}$ is the molecular weight of $\varepsilon-\mathrm{CL}$ monomer.

$\operatorname{Ratio}\left(\mathrm{PCL}: \mathrm{PMEO}_{2} \mathrm{MA}\right)=\operatorname{Ratio}\left(\mathrm{CL}: \mathrm{MEO}_{2} \mathrm{MA}\right)\left(\frac{\mathrm{MPMEO}_{2} \mathrm{MA} / \mathrm{MMEO}_{2} \mathrm{MA}}{\mathrm{MPCL} / \mathrm{MCL}}\right)$

\section{Graft density calcualtion of polymer brushes on AuNPs}

Given the size of a gold atom $\left(0.017 \mathrm{~nm}^{3}\right)$, the number of gold atom $\left(\mathrm{N}_{\mathrm{Au}}\right.$ atom $)$ in $14 \mathrm{~nm}$ Au nanoparticles could be calculated using Equation S2, where $\mathrm{R}$ was the radium of the gold nanoparticles. The result was 84472 gold atoms per nanoparticle and therefore the molar mass $\left(\mathrm{M}_{\mathrm{Au}}\right.$ nanoparticle) of the gold nanoparticle was $197 \mathrm{~N}_{\mathrm{Au} \text { atom. }}$. Combining the molar mass of the gold nanoparticle, the ratio of PCL and $\mathrm{PMEO}_{2} \mathrm{MA}$ and the weight fraction obtained from the TGA analysis, the numbers of polymer grafts $\left(\mathrm{N}_{\mathrm{PCL}}\right.$ and $\mathrm{N}_{\text {PMEO2MA }}$ ) could be calculated by Equation S3 and $\mathrm{S} 4$, where $\mathrm{W}_{\text {polymer }}$ was the weight fraction of the organic part.

$$
\begin{aligned}
& \mathrm{N}_{\text {Au atom }}=\frac{\mathrm{V}_{\text {AuNP }}}{\mathrm{V}_{\text {Au atom }}}=\frac{4 \pi}{3}\left(\frac{\mathrm{R}^{3}}{\mathrm{~V}_{\text {Au atom }}}\right) \\
& \mathrm{N}_{\text {PMEO2MA }}=\frac{M_{\text {Au nanoparticles }}\left(\mathrm{W}_{\text {polymer }} / 1-\mathrm{W}_{\text {polymer }}\right)}{\text { MPCL }_{\text {Raito }}\left(\mathrm{PCL}: \mathrm{PMEO}_{2} \mathrm{MA}\right)+\mathrm{MPMEO}_{2} \mathrm{MA}} \\
& \text {...(S3) } \\
& N_{\text {PCL }}=\frac{M_{\text {Au nanoparticles }}\left(W_{\text {polymer }} / 1-W_{\text {polymer }}\right)}{\text { MPCL*Raito(PCL:PMEO2MA }+ \text { MPMEOMA }} * \text { Raito(PCL:PMEO2MA) } \\
& \text {...(S4) }
\end{aligned}
$$

\section{Characterizations}

The structures of PCL, $\mathrm{PMEO}_{2} \mathrm{MA}$ and $\mathrm{Au} @ \mathrm{PCL} / \mathrm{PMEO}_{2} \mathrm{MA}$ were examined by NMR (Bruker Avance $600 \mathrm{MHz}$, Bruker AXS Inc, Madison, Wisconsin). The morphology of the gold assemblies (GAs) was observed by transmission electron microscope (TEM, JEOL 2100F) at $200 \mathrm{kV}$ and field emission scanning electron microscope (FESEM, JSM 6700F). Thermo gravimetric analysis (TGA) was obtained using a TG-209-F3 thermo gravimetric analyzer (Netzsch Instruments, Germany) with a heating rate of 10 ${ }^{\circ} \mathrm{C} / \mathrm{min}$ from 30 to $700{ }^{\circ} \mathrm{C}$ in $\mathrm{N}_{2}$ atmosphere. The STEM and EDS measurements were carried out using field emission transmission electron microscopy (FETEM, Tecnai G2 F30). UV vis spectrophotometry measurements were performed on TU-1810 ultraviolet and visible spectrophotometer (Persee, China) with wavelength range from $400 \mathrm{~nm}$ to $1100 \mathrm{~nm}$. ICP-MS measurement for gold materials were performed on 
inductively coupled plasma mass spectrometry (Agilent 7500ce). The photothermal images were obtained by using thermal camera (FLIR, T330) running on FLIR tools systems.

\section{Photothermal performance in solution}

GAs solutions were diluted to $0.1 \mathrm{mg} / \mathrm{mL}$ and then were exposed to an $808 \mathrm{~nm}$ NIR laser at a power density of $1 \mathrm{~W} / \mathrm{cm}^{2}$ for $10 \mathrm{~min}$. A thermocouple was used to measure the temperature every $60 \mathrm{~s}$.

\section{Photothermal Treatment with NIR Light in vitro and TEM study}

Human breast cancer cell (MCF-7) was endowed by National Center for Nanoscience and Technology. The DMEM supplemented with 10\% PBS were utilized as the cell culture medium. Cells were cultured at $37^{\circ} \mathrm{C}$ in a humidified atmosphere of $5 \% \mathrm{CO}_{2}$ and 95 $\%$ air. For in vitro studies MCF-7 cells were incubated with $0.1 \mathrm{mg} / \mathrm{mL}$ GAs in 96-well cell culture plate at 37 ${ }^{\circ} \mathrm{C}$ and $5 \% \mathrm{CO}_{2}$. After internalization with GAs for 4 $\mathrm{h}$, cells were washed 3 times with PBS and irradiated by an $808 \mathrm{~nm}$ NIR laser at a power density of $1 \mathrm{~W} / \mathrm{cm}^{2}$ for $10 \mathrm{~min}$. A standard cell viability assay 3-(4, 5-dimethylthiazol-2-yl)-2, 5-diphenyltetrazolium bromide (MTT) was conducted to determine the cell killing efficiency after photothermal ablation. Cell viability was normalized to a control group without any treatment.

For TEM study, after incubated with GA7 (0.1 $\mathrm{mg} / \mathrm{mL}$ ), MCF-7 cells incubated were fixed in $0.25 \%$ glutaraldehyde in PBS and postfixed in 1\% osmium tetraoxide, dehydrated in ascending concentrations of ethanol and embedded in Epon 812. Ultrathin sections prepared were lightly stained with $1 \%$ uranyl acetate and lead citrate, and observed with JEOL 2100F.

\section{Photothermal treatment with NIR Light in vivo}

Female BALB/c nude with mice 5-7 weeks old were purchased from the Academy of Military Medical Sciences of China. All protocols for this animal study were conformed the Guide for the Care and Use of Laboratory Animals. All procedures involving experimental animals were performed in accordance with protocols approved by the Committee for Animal Research of Peking University, China. MCF-7 cells $\left(5 \times 10^{6}\right.$ in $100 \mu \mathrm{L}$ PBS) were injected subcutaneously into the left axillary areas of the mice to induce solid tumors. When the tumor volumes reached about 100-200 mm 3 , bearing MCF-7 tumors were intradermally injected with $50 \mu \mathrm{L}$ of $2 \mathrm{mg} / \mathrm{mL}$ GAs and then irradiated with the $808 \mathrm{~nm}$ NIR laser at power density of $1 \mathrm{~W} / \mathrm{cm}^{2}$ for $5 \mathrm{~min}$. Real-time thermal imaging of MCF-7 tumor was monitored with FLIR. After treatment, the MCF-7 tumor volume was monitored for two weeks continuously. Tumor dimensions were determined at numerous time points using a caliper. Tumor volume $(\mathrm{V})\left(\mathrm{mm}^{3}\right)$ was calculated using the following formula: $V=a \times b^{2} / 2$, where $a$ is the length and $b$ is the width in millimeters, respectively. Comparative tumor volumes were calculated as $\mathrm{V} / \mathrm{V}_{0}$, where $\mathrm{V}_{0}$ is the original tumor volume before the treatment was started.

\section{Histopathology assessments}

Two weeks after the PTT, animals were sacrificed and main organs (heart, liver, spleen, lung and kidney) were harvested and fixed in $10 \%$ neutral buffered formalin for 24 hours, and then decalcified overnight, and processed through a gradient of alcohols then embedded in paraffin. Hematoxylin-eosin staining slides were immersed in the stain, washed, and mounted in p-xylene-bis-pyridiniumbromide (VWR, Dorset, England) with obtained tissues section of $5 \mu \mathrm{m}$.

\section{In vivo $\mathrm{CT}$ imaging}

For tumor imaging, Mice were anesthetized by inhalation anesthesia (1.5\% isoflurane in 1:2 $\left.\mathrm{O}_{2} / \mathrm{N}_{2}\right)$. After animals being intratumorally injected with 50 $\mu \mathrm{L}$ of $2 \mathrm{mg} / \mathrm{mL}$ GA, CT images were taken immediately. CT data were acquired using a high resolution Micro-CT system (Quantum FX, Caliper). Parameters were listed as follows: slice thickness, 0.625 $\mathrm{mm}$; pitch, $0.984: 1 ; 120 \mathrm{kVp}, 500 \mathrm{~mA}$; field of view, 512x512; gantry rotation time, $0.4 \mathrm{~s}$; table speed, 40 $\mathrm{mm} /$ rotation. Animals were scanned from the lower chest to the neck.

\section{Results and Discussion}

\section{Synthesis and assembly of PCL and $\mathrm{PMEO}_{2} \mathrm{MA}$ grafted AuNPs}

The AuNPs functionalized with hybrid polymers inherited the distinct chemical property from amphiphilic polymers, which endowed the AuNPs ability to self-assembly. Therefore, it was reasonable that the structures of the building polymer could influence the LSPR of AuNPs assembly. Biocompatible PCL was selected as the hydrophobic brushes, since PCL was a semicrystalline polymer [34] with good flexibility [35], which might be benefit for reducing the interparticle distance after self-assembly of polymer grafted AuNPs. Ring open polymerization of PCL was initiated by a small bromine ended initiator of $\mathrm{HMB}$, and then a modified two step thiolation method developed by R. Paris [36] was adopted for the synthesis of PCL-SH: (1) transforming the bromine into thio-ester by reaction with potassium thioacetate; (2) reducing the thio-ester into thiol. In R. Paris's method, the redactor sodium methoxide might hydrolyze PCL. To avoid the hydrolysis, a milder reagent hydrazine hy- 
drate was employed for preparation of PCL-SH. In addition, the bromine in the HMB could initiate the ATRP, this new thiolation route could also be extended to produce thiol end-functioned ATRP polymer. The biocompatible polymer $\mathrm{PMEO}_{2} \mathrm{MA}$, which had been used in a wide spectrum of biological applications [37-39] was produced through this strategy (Supplementary Material: Scheme S1) and selected as hydrophilic brush.

The synthesis of PCL and $\mathrm{PMEO}_{2} \mathrm{MA}$ was verified by ${ }^{1} \mathrm{H}$ NMR measurement $[40,41]$. In the ${ }^{1} \mathrm{H}$ NMR spectral of $\mathrm{PMEO}_{2} \mathrm{MA}$ (Figure 1), it showed the resonance of $-\mathrm{CH}_{2} \mathrm{OCH}_{2} \mathrm{CH}_{2} \mathrm{O}-\left(3.5-3.7 \mathrm{ppm}\right.$ ), $-\mathrm{COOCH}_{2}-$ (4.1 ppm), $-\mathrm{OCH}_{3}(3.4 \mathrm{ppm})$ of $\mathrm{PMEO}_{2} \mathrm{MA}$. And according to the ratio of the resonance of $-\mathrm{COOCH}_{2}-(4.1$ ppm) and that of methyl $(1.15 \mathrm{ppm})$ of the initiator $\mathrm{HMB}$, the degree of polymerization $(\mathrm{DP}=50)$ and the molecular weights of $\mathrm{PMEO}_{2} \mathrm{MA}(\mathrm{Mn}=10 \mathrm{KDa})$ could be calculated. In the ${ }^{1} \mathrm{H}$ NMR spectral of PCL (Figure 1), the resonance of $-\mathrm{CH}_{2} \mathrm{CO}-(2.4 \mathrm{ppm}),-\mathrm{OCH}_{2^{-}}(4.1$ ppm), $-\mathrm{CH}_{2} \mathrm{CH}_{2} \mathrm{CH}_{2-}$ (1.4-1.6 ppm) indicated the synthesis of PCL. Moreover, by calculating the ratio of the resonance of $-\mathrm{CH}_{2} \mathrm{CO}-(2.49 \mathrm{ppm})$ of $\mathrm{CL}$ and that of methyl (1.94 ppm) of the initiator HMB, the DP and molecular weights of PCL were deduced as 240 and 27 $\mathrm{KDa}$ respetively. Because of the strong Au-S bonds between thiol end group and AuNPs, thiol-functionalized polymers (PCL-SH and $\mathrm{PMEO}_{2} \mathrm{MA}-\mathrm{SH}$ ) could graft onto AuNPs, forming amphiphilic AuNPs. In the ${ }^{1} \mathrm{H}$ NMR spectral of amphiphilic AuNPs (Figure 1C), the feature peaks of PCL and $\mathrm{PMEO}_{2} \mathrm{MA}$ verified the formation of amphiphilic AuNPs. It was known that ratios of the hydrophilic and hydrophobic components would affect the assembly morphologies of amphiphilic AuNPs [42]. In our study, we prepared a series of amphiphilic $\mathrm{Au} @ \mathrm{PCL} / \mathrm{PMEO}_{2} \mathrm{MA}$ nanoparticles with different $\mathrm{PCL} / \mathrm{PMEO}_{2} \mathrm{MA}$ ratios, while maintaining the same chain length of PCL $(27 \mathrm{kDa})$ and $\mathrm{PMEO}_{2} \mathrm{MA}(10$ $\mathrm{kDa})$.

In detail, the "grafting to" reaction was used, by simultaneously putting the PCL-SH and $\mathrm{PMEO}_{2} \mathrm{MA}-\mathrm{SH}$ with different ratios into the mixed solvent and reacting with the AuNPs through covalent Au-S bonds, a series of amphiphilic AuNPs with different PCL/ $\mathrm{PMEO}_{2} \mathrm{MA}$ chain ratios could be obtained. The actual results of the actual molar ratio of PCL and $\mathrm{PMEO}_{2} \mathrm{MA}$ on an AuNPs could be calculated from the ${ }^{1} \mathrm{H}$ NMR measurements (Supplementary Material: Figure S1). Based on the molecular weight information of PCL $(27 \mathrm{kDa})$ and $\mathrm{PMEO}_{2} \mathrm{MA}(10 \mathrm{kDa})$ and the weight fraction of organic polymer brushes measured by thermo gravimetric analysis (TGA) (Supplementary Material: Figure S2), the numbers of the chain of PCL and $\mathrm{PMEO}_{2} \mathrm{MA}$ on single AuNPs could be deduced as shown in Table 1. For convenience, we defined the five sorts of AuNPs with different PCL: $\mathrm{PMEO}_{2} \mathrm{MA}$ molar ratio as AuNP1, AuNP2, AuNP3, AuNP7 and AuNP13 respectively.

Table I.PCL/ PMEO 2 MA ratios of AuNPs/GAs

\begin{tabular}{llll}
\hline & $\begin{array}{l}\text { Chain number of } \\
\text { PCL }\end{array}$ & $\begin{array}{l}\text { Chain number of } \\
\text { PMEO }_{2} \mathrm{MA}\end{array}$ & $\begin{array}{l}\text { PCL/PMEO } \\
\text { ratio }\end{array}$ \\
\hline AuNP1/GA1 & 76 & 96 & $0.8: 1$ \\
AuNP2/GA2 & 120 & 60 & $2: 1$ \\
AuNP3/GA3 & 140 & 46 & $3: 1$ \\
AuNP7/GA7 & 168 & 24 & $7: 1$ \\
AuNP13 & 170 & 13 & $13: 1$ \\
\hline *GA1, GA2, GA3 and GA7 were defined as the assembly composed by AuNP1, \\
AuNP2, AuNP3 and AuNP7 respectively. AuNP13 can not self assembly into \\
nano-structures because of the extremely high PCL/PMEO 2 MA ratio.
\end{tabular}

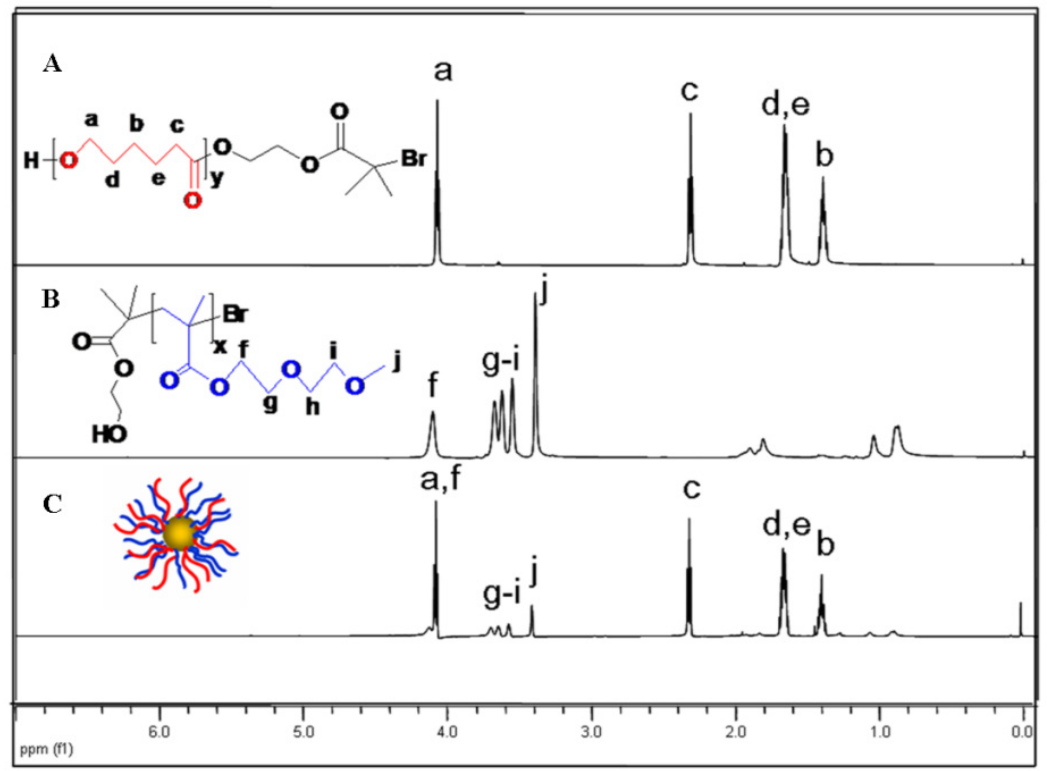

Figure I. 'H NMR spectra of (A) PCL, (B) PMEO $2 M A$ and (C) Au@PCL/PMEO $2 M A$ 


\section{Self-Assembly of the amphiphilic AuNPs}

Five sorts of amphiphilic AuNPs with different $\mathrm{PCL} / \mathrm{PMEO}_{2} \mathrm{MA}$ molar ratios mentioned above were used as building blocks for self-assembly. By adding water, the hydrophobic brush PCL collapsed on the surface of AuNPs to minimize the overall free energy of the system, resulting in the assembly of amphiphilic AuNPs into 3D nano-structures (except for AuNP13, this sort of AuNPs turned into flocculation during the process of self-assembly which could be seen in Supplementary Material: Figure S3). The gold assembly composed by them was defined as GA1, GA2, GA3 and GA7 respectively as shown in Table 1. The TEM and SEM images (Figure 2A) of GA1, GA2 and GA3 showed a characteristic hollow vesicle structures with a clear contrast between the interior and the shell, and their size ranged from $100 \mathrm{~nm}$ to $300 \mathrm{~nm}$ which was in agreement with the results of dynamic light scattering (DLS) mesurement (as shown in Figure 2C).

However, the SEM and TEM images of GA7 showed a totally different appearance with the vesicular assemblies, in which the clear contrast between the interior and the shell disappeared and its size increased to around $500 \mathrm{~nm}$. Since the SEM and TEM images were two-dimensional projections of three-dimensional objects, it was difficult to clearly verify the interior structures of GA7. According to So-Jung Park's work [43], STEM and EDS measurements were employed to further confirm the structure of GA7 (Figure 3A). The characteristic vesicle structure of GA2 was chosen as comparison. The Au intensity line scan of vesicle structure prepared by GA2 showed higher Au intensity at the spherical interface, two peaks appeared at two ends of line scan and a wave trough appeared in the middle region. This result was in agreement with the hollow interior vesic-
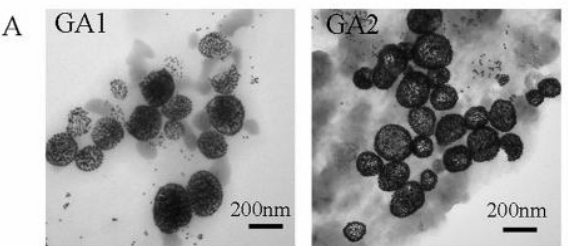

B

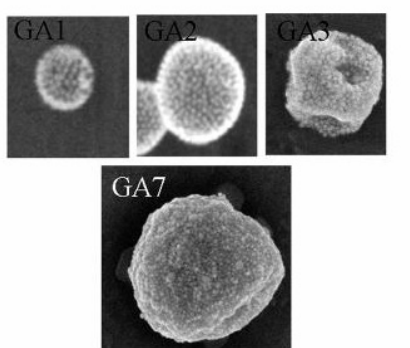

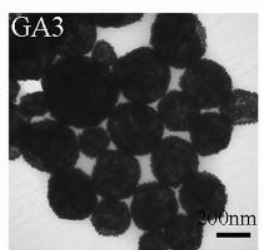

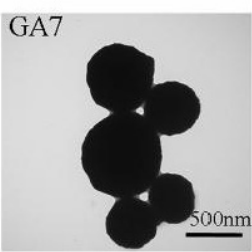

ular structure. Moreover, the two peaks at both sides of the line scan were fitted with a Gaussian function (Supplementary Material: Figure S4). The full width at half maximum (FWHM) was determined to be about $17 \mathrm{~nm}$ from the fitting, indicating the shell thickness of GA2 was about $17 \mathrm{~nm}$. Since the assembly was made up by $14 \mathrm{~nm}$ AuNPs, it could be deduced that the vesicle was composed of a monolayer shell of AuNPs. On the contrary, the Au line scan of GA7 exhibited a totally different curve from GA2. There were no obvious peaks and nadirs in the curve and the $\mathrm{Au}$ intensity was generally strong along the line, which indicated that nanoparticles are homogeneously distributed inside the polymer matrix ball. As reported by Adi Eisenberg [32], when molar hydrophobic / hydrophilic ratio increased to a very high degree, the amphiphilic compounds tend to self-assembly into large compound micelles (LCM) which could be seen as a big solid copolymer ball filled with reverse micelles. GA7 shared many similarities with LCM for their large size, solid interior and high hydrophobic/hydrophilic ratio, which indicated that the GA7 might possess the structure of LCM. As shown in scheme 1 , this structure was similar to densely packed big cluster of AuNPs, and the hydrophobic polymer PCL and hydrophilic polymer $\mathrm{PMEO}_{2} \mathrm{MA}$ on AuNPs would separated forming reverse micelles which were dotted in the core. The structural difference between GA7 and GA2 was also confirmed by their ultrathin section (Figure 3B). GA2 was vesicle composed by a monolayer AuNPs with hollow interior which was agreement with STEM and EDX measurements. However the interior of GA7 was solid and almost full of AuNPs. These results suggested that by changing the PCL/PMEO ${ }_{2} \mathrm{MA}$ ratio, a novel gold LCM can be obtained.

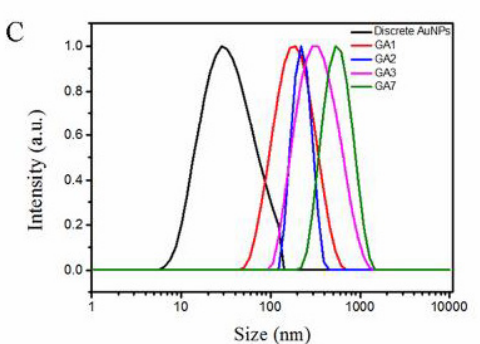

Figure 2. (A) TEM images, (B) SEM images and (C) hydrodynamic sizes of GAI, GA2, GA3 and GA7 
A
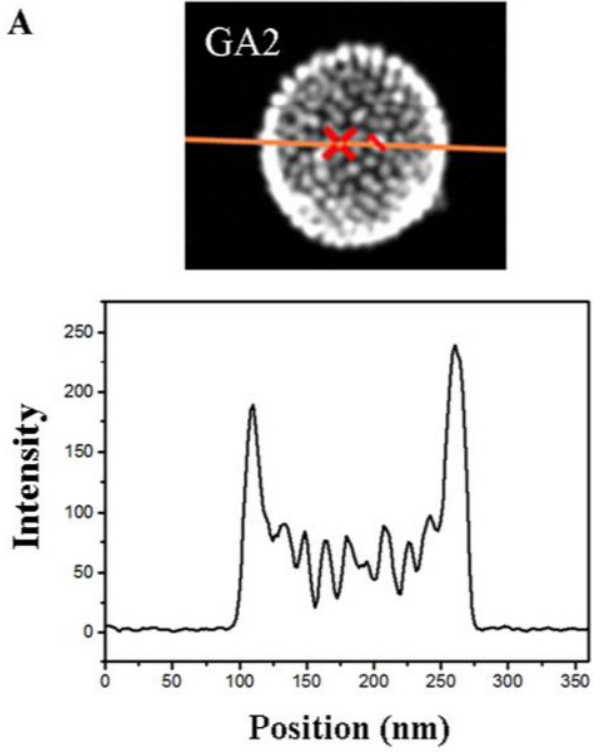

B

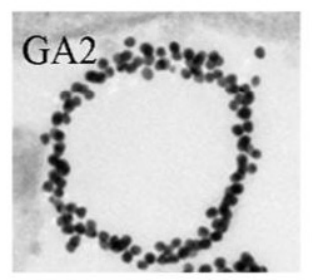

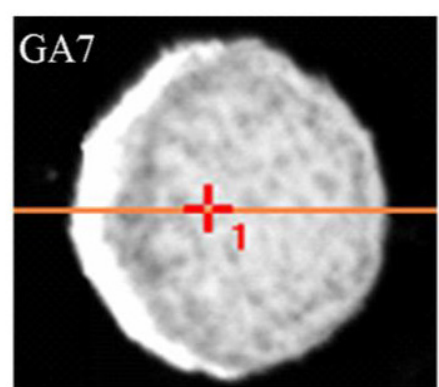
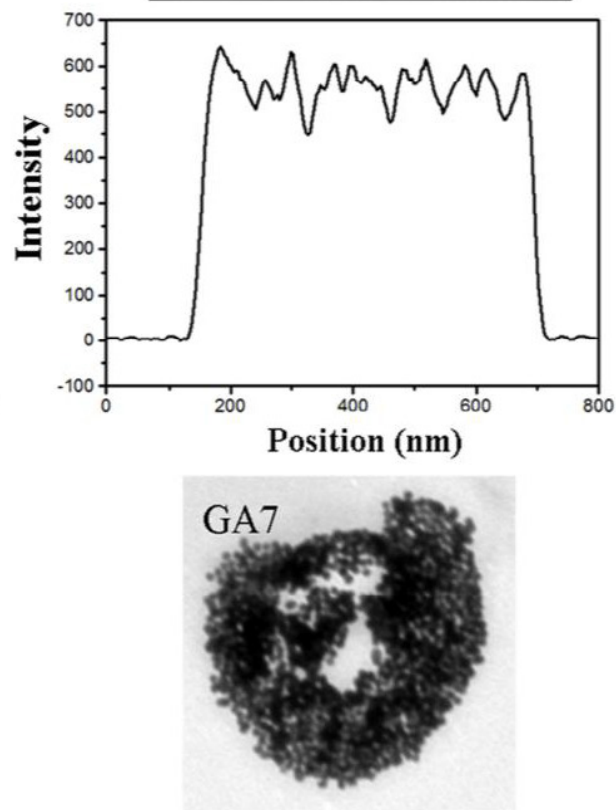

Figure. 3. (A) Structural characterization and Au intensity line scan of gold assemblies GA2 and GA7. (B) Ultrathin section TEM images of GA2 and GA7.

\section{The enhanced LSPR performance induced by self-assembly}

During the self-assembly of amphiphilic AuNPs, collapsed PCL chains on the surface of AuNPs formed the hydrophobic polymer domains and pull AuNPs together, resulting in the distance reduction between nanoparticles with a red-shift of LSPR peak. The hydrophilic $\mathrm{PMEO}_{2} \mathrm{MA}$ played dual roles in the process of assembly, they extended to the aqueous environment stabilizing the assemblies, and on the other hand they caused strong steric hindrance for the nanoparticles to approach each other [44]. Although GA1, GA2 and GA3 were all vesicle, their spectral shifts were highly dependent on the relative ratio of PCL and $\mathrm{PMEO}_{2} \mathrm{MA}$. Amphiphilic AuNPs with $\mathrm{PCL} / \mathrm{PMEO}_{2} \mathrm{MA}$ ratios of $0.8: 1,2: 1$ and 3: 1 gave rise to vesicles with LSPR centered at $550 \mathrm{~nm}, 610 \mathrm{~nm}$ and $675 \mathrm{~nm}$ (Figure 4). A less fraction of $\mathrm{PMEO}_{2} \mathrm{MA}$ caused weaker steric hindrance for nanoparticles to approach each other, therefore leading to small interparticle distances ( in detail, the interparticle distances of GA1, GA2 and GA3 reduced from $10 \mathrm{~nm}, 7$ $\mathrm{nm}$ and to $4 \mathrm{~nm}$, which could be also confirmed by
TEM and SEM images) and stronger plasmonic coupling. When the $\mathrm{PCL} / \mathrm{PMEO}_{2} \mathrm{MA}$ ratio increased to $7: 1$, the steric hindrance caused by $\mathrm{PMEO}_{2} \mathrm{MA}$ was faint, thinner $\mathrm{PMEO}_{2} \mathrm{MA}$ layer could not protect the hydrophobic wall of the vesicle any more, vesicles tended to attract each other and fused into LCM, and the interparticle distance of GA7 was less than $2 \mathrm{~nm}$. In this situation, AuNPs of GA7 were packed so strictly that its LSPR red-shifted drastically to $830 \mathrm{~nm}$ (Figure 4) which belonged to NIR region.

\section{Photothermal conversion and degradation of GAs in vitro}

The strong absorption in the NIR region and the ability to disintegrate into discrete AuNPs made it possible to use GA7 as photothermal conversion agent. To verify the different NIR absorption optical properties of the four types of GAs and their applications in PTT, $0.1 \mathrm{~g} / \mathrm{mL}$ GAs solutions were exposed to an $808 \mathrm{~nm}$ NIR laser at a power density of $1 \mathrm{~W} / \mathrm{cm}^{2}$ for $10 \mathrm{~min}$. According to Figure 5A, GA1, GA2 and GA3 showed a poor heating effect, the temperature of their aqueous solution increased $4{ }^{\circ} \mathrm{C}, 7^{\circ} \mathrm{C}$ and $12^{\circ} \mathrm{C}$ respectively. By contrast the temperature of $\mathrm{GA} 7$ 
aqueous solution increased $23^{\circ} \mathrm{C}$ because of its strong NIR absorption. The heating effect of GAs was also related to the concentrations of GAs. For example, GA7 aqueous solution with different concentrations from $0,0.025,0.050$, and to $0.1 \mathrm{mg} / \mathrm{mL}$ were exposed to an $808 \mathrm{~nm}$ NIR laser at a power density of $1 \mathrm{~W} / \mathrm{cm}^{2}$, the temperature increased $1.6^{\circ} \mathrm{C}, 7^{\circ} \mathrm{C}, 14^{\circ} \mathrm{C}$ and $23^{\circ} \mathrm{C}$ respectively (Supplementary Material: Figure $\mathrm{S} 5)$.

A

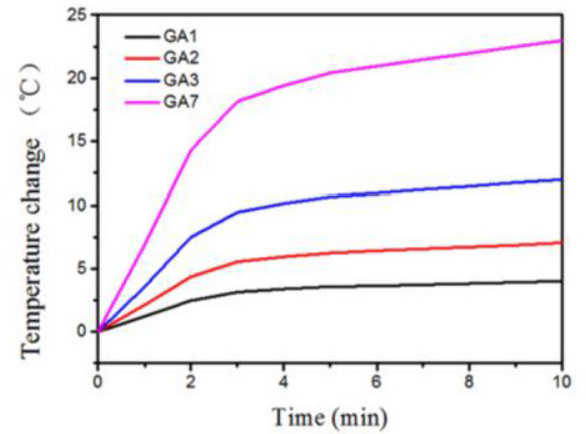

C

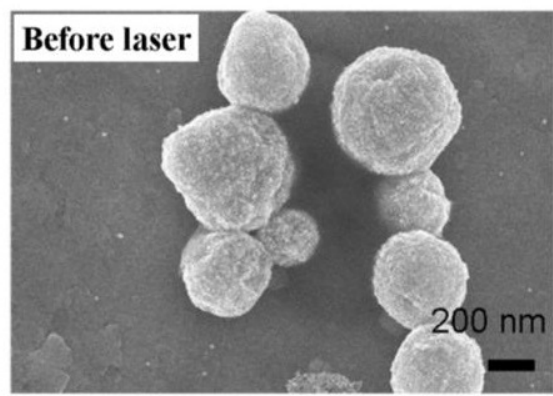

$\mathrm{D}$

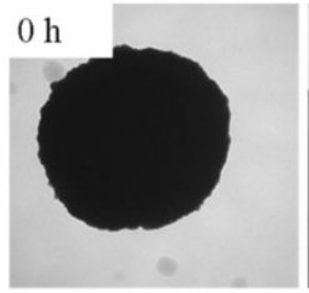

$12 \mathrm{~h}$

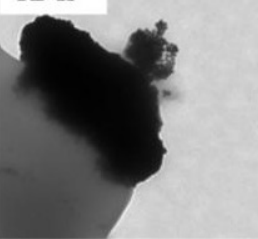

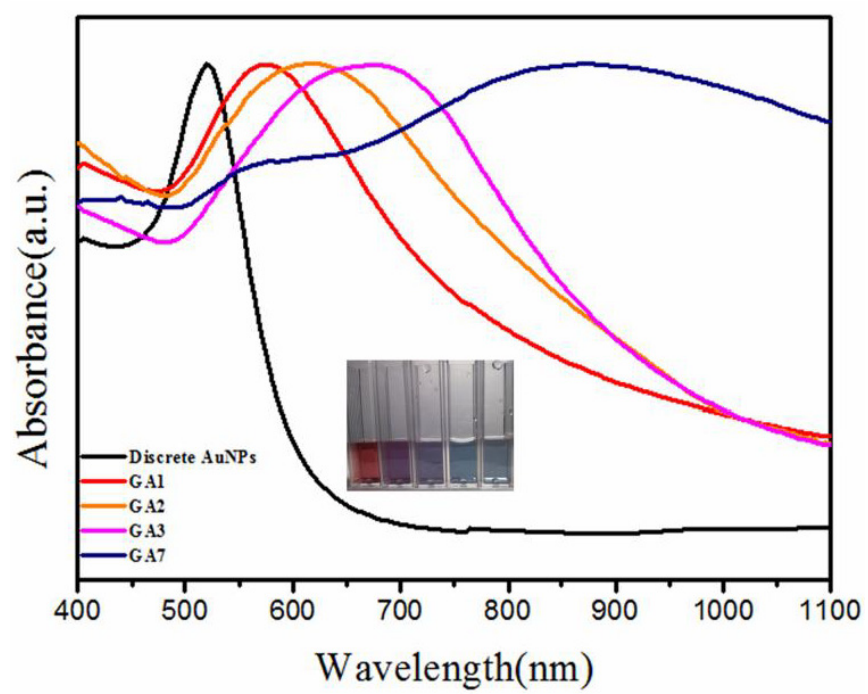

Figure 4. The UV/Vis/NIR spectra of the four sorts of GAs. Insert figure shows the digit picture of the solutions of discrete AuNPs, GAI, GA2, GA3 and GA7 (from left to right) respectively.
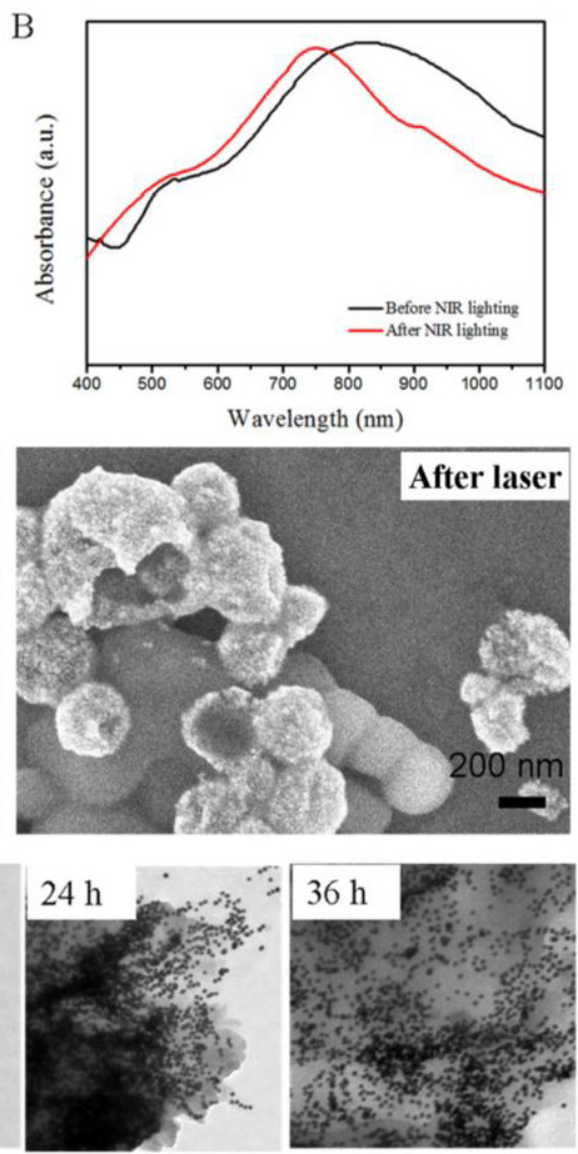

Figure 5. (A) The temperature elevation curves of aqueous solution of GAs. (B) The UV/Vis/NIR spectra of GA7 before (left) and after (right) NIR lighting. (C) The SEM images of GA7 before and after NIR lighting. (D) The TEM images of the GA7 before and after incubated with esterase solution at I $2 \mathrm{~h}, 24$ $h$ and $36 \mathrm{~h}$ respectively. 
Because only GA7 showed strong NIR absorption and good photothermal effect, it was chosen for further explore. We measured the photothermal conversion efficiency of the GA7 according to Nie's work [25], the photothermal conversion of GA7 was about to be $23 \%$ which was closed to corresponding values for gold nanorods $(22 \%)$, and higher than nanoshells (13\%) [25]. According to Duan' research, these amphiphilicity-driven gold assemblies might break down after NIR lighting [28], which was not benefit for the photothermal stability. We took the GA7 sample for SEM measurement after NIR irradiation. The SEM image (Figure 5C) showed that the LCM structure had slight fracture but had not been destroyed thoroughly. And the absorption spectra of the GA7 after NIR irradiation just show a slight bule-shift compared to the sample without NIR irradiation (Figure 5B), which suggested LCM possessed a certain degree of photothermal stability. This photothermal stability might be contributed to the tightly packed structure of LCM. Even though the GA7 could not be totally destroyed under NIR irradiation, it can decomposed when the hydrophobic grafts PCL was hydrolyzed. In our experiment, esterase was used to induce the hydrolysis of GA7 in vivo. GA7 was incubated in solution of esterase $(25 \mathrm{U} / \mathrm{mL})$ under $37{ }^{\circ} \mathrm{C}$ with mild stirring. According to the TEM images (Figure 5C), with the hydrolysis of esterase, the PCL gradually degraded which induced the structure collapse of GA7 and finally dissociation into discrete AuNPs after $36 \mathrm{~h}$. It should be noted that the conditions in living body is more complex with abundant enzymes, and the GA7 could disintegrate into discrete AuNPs. These results suggested that GA7 could be potential photothermal agents with a certain extent of photothermal stability under NIR irradiation; on the other hand it could be hydrolyzed into discrete AuNPs, which benefit the clearance of these gold nanomaterials.

\section{Photothermal therapy and in vitro}

To further verify the suitability of GA7 as photothermal therapy agents, NIR-laser-triggered cell-killing effect of the GA7 to MCF-7 cells was assessed by MTT assay (Figure 6A) and other GAs were choose as control group. Even though the sizes of these gold assemblies were big, they could still get into cell. For example, after MCF-7 cell was incubated with GA7 for $1 \mathrm{~h}, 2 \mathrm{~h}, 3 \mathrm{~h}$ and $4 \mathrm{~h}$, the ICP-MS measurements showed that the cellular uptake percentage of GA7 reached from $20 \%, 28 \%, 35 \%$ and to $40 \%$

B

C
(Supplementary Material: Figure S6). With no laser irradiation, the GAs exhibited negligible toxicity to MCF-7 cells, which more than $90 \%$ of the cell remained viable. After laser irradiation, the GAs induced NIR absorption-dependent cytotoxicity to MCF-7 cells. The cell viability of irradiated groups gradually decreased as the NIR absorption ability of GAs increased. With limited ability of NIR absorption, GA1 and GA2 were almost innocuous to cell, and less than $20 \%$ cells were killed. While GA3 had better NIR absorption ability than GA1 and GA2, more cell apoptosis was observed with cell viability reducing to $50 \%$. GA7 showed the best ability to absorb NIR laser, the highest cell mortality rates were observed $87 \%$ cells killed respectively.

To further identify cell viability, the cells were stained with Calcein AM and propidium iodide immediately following PTT with GA7 in which dead cell would be stained red while live cells were stained green. In the control groups without laser illumination, all cells displayed green fluorescence. Representative color picture was shown in Figure. 6B. This result indicated that the selected NIR light irradiation power cause no obvious damage to the MCF-7 cells.

A
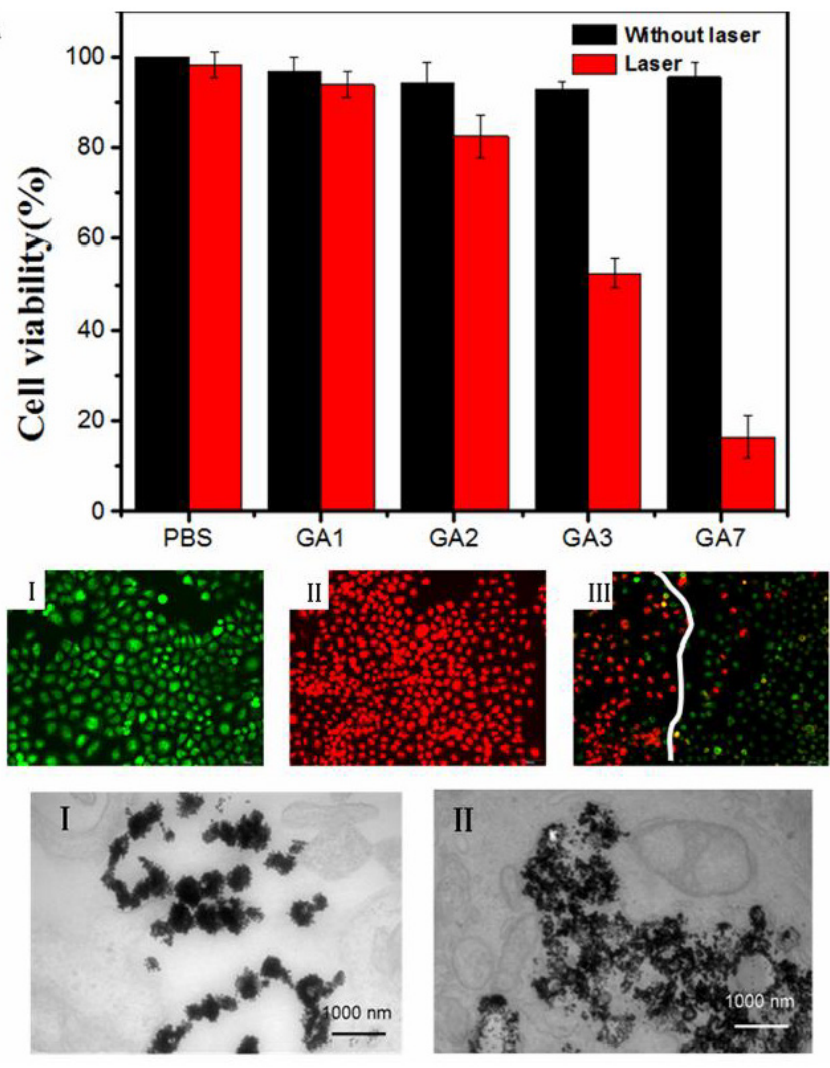

Figure 6. (A) MCF-7 cell viability incubated with different types of GAs for $4 \mathrm{~h}$ at 37 ${ }^{\circ} \mathrm{C}$, then the cells were illuminated using a $808 \mathrm{~nm}$ laser $\left(1 \mathrm{~W} / \mathrm{cm}^{2}, 10 \mathrm{~min}\right)$. (B) Fluorescence images of Calcein AM and PI co-stained cancer cells: (II) without GAs (laser only), (IIII) incubated with GA7 at the center spot of laser irradiation, (IIIII) incubated with GA7 at the edge of laser spot. (C) The ultrathin sections TEM of GA7 incubated with MCF-7 before laser (II) and after laser (IIII). 
For the irradiated group, an intense homogeneous fluorescence red can be seen in almost all cells (Figure 6B), which suggested that most cells were killed. Meanwhile, the Figure 6B showed that only cells within the laser spot were killed, whereas cells outside the region of the laser spot displayed green fluorescence. This result indicated that PTT treatment with the GA7 was highly selective and localized.

The degradation of GA7 was also assessed at cellular level. According to the ultrathin sections TEM images (Supplementary Material: Figure S7), a large number of GA7 was observed in the cells. Before the NIR irradiation the GA7 structure showed a slight extent of decompose (Figure 6C) which might be contributed to the hydrolysis of PCL by esterase in cells. And after NIR irradiation, the decomposition of GA7 was aggravated (Figure 6C) and showed a tendency of totally being disintegrated into discrete AuNPs. These results suggested that GA7 could be broken down into smaller discrete AuNPs then followed by a rapid clearance of small AuNPs.

\section{Photothermal imaging in vivo}

Followed by the in vitro PTT test of the GAs, we then investigated the feasibility of using the GAs as photosensitize in vivo by employing PT imaging (Figure 7A) to record the temperature change under $808 \mathrm{~nm}$ laser irradiation. Since the wavelength of monochromatic $808 \mathrm{~nm}$ laser was mostly focused at the region from $798 \mathrm{~nm}$ to $818 \mathrm{~nm}$, that meant only GA7 with LSPR peak closest to $808 \mathrm{~nm}$ could absorb and convert NIR light to heat energy most efficiently among three sorts of GAs in our study. The mice were treated by intratumoral injection with GAs solution or PBS and then laser irradiation imposed on tumor site at a power of $1 \mathrm{~W} / \mathrm{cm}^{2}$. For PBS control group, no significant temperature increase was observed. As the control groups treated with GA1 and GA3, the average local tumor temperature just increased to $43.7^{\circ} \mathrm{C}$ and $44.6^{\circ} \mathrm{C}$ within 5 min respectively (Figure 7B). The

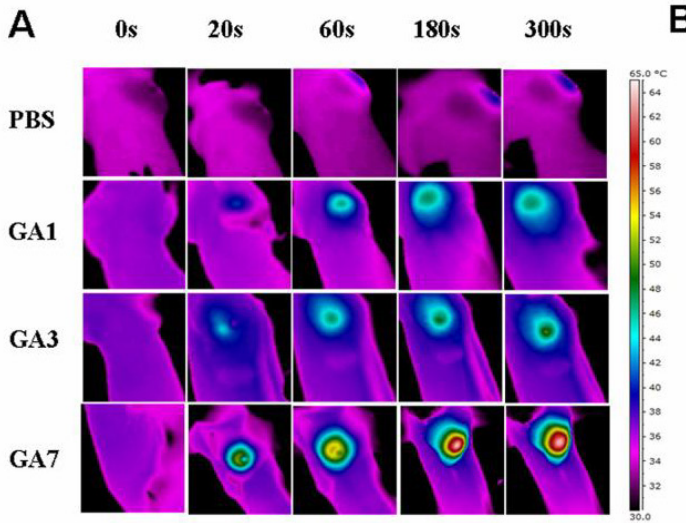

photothermal conversion ability of GA7 was clearly superior than that of GA1 and GA3, the average local tumor temperature treated with GA7 rapidly increased to $60^{\circ} \mathrm{C}$ (Figure 7B) within 5 min which exceed the damage threshold necessary [45].

\section{Photothermal therapy in vivo}

The GAs induced photothermal cancer therapy in vivo was further studied in MCF-7 tumor-bearing nude mice. Mice were intratumorally injected with PBS solution of GA1, GA3, and GA7 respectively and then exposed to $808 \mathrm{~nm}$ laser immediately. For comparison, blank group mice without injection of GAs or without exposure to the $808 \mathrm{~nm}$ laser were chosen as the control groups. As observed from Figure 8A, all of the groups without laser irradiation tumors grew rapidly and the highest relative tumor volume $\left(\mathrm{V} / \mathrm{V}_{0}\right)$ could be as high as about 7 within two weeks. In GA1 group and PBS group under laser exposure, their tumor growth curves showed the similar trend of those groups without laser irradiation, suggesting negligible effect on impeding tumor development. As for the GA3 group, laser irradiation showed weak inhibiting effect to tumor growth and the $\mathrm{V} / \mathrm{V}_{0}$ value still increased to 5.67 two weeks later, indicating that heat energy generated by GA3 was not enough to destroy tumor cells completely. In the group administered with GA7 and irradiated with laser, tumors were ablated with black scars left at the original tumor sites (Figure $8 \mathrm{~B})$ and the relative tumor volume $\left(\mathrm{V} / \mathrm{V}_{0}\right)$ had shrunk to 0 , indicating the superior thermal therapy effect of GA7. Furthermore, the tumors treated with GA7 were harvested for hematoxylin andeosin (H\&E) staining (Figure 8C). In the histology studies, severe cellular damage in the test group was observed in comparison with the control and blank groups. These observations demonstrated that the GA7 injected tumor cells were severely damaged after laser irradiation.

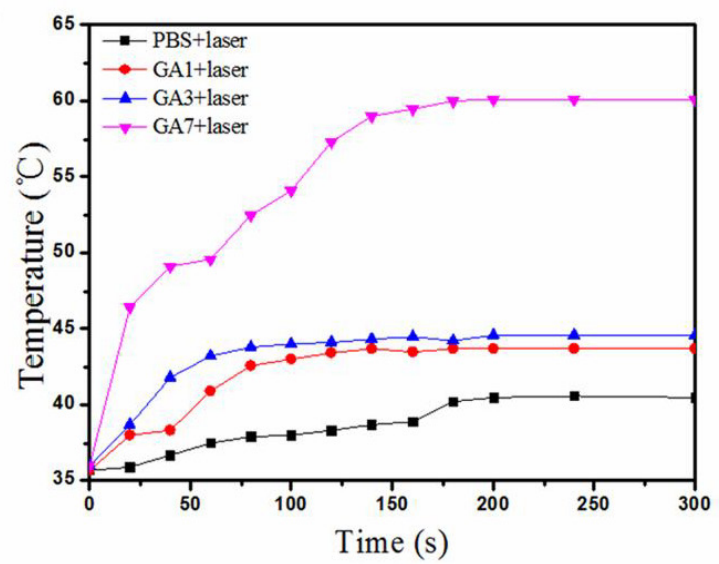

Figure 7. (A) Thermal images of MCF-7 tumor-bearing mice exposed to an $808 \mathrm{~nm}$ laser for 5 min after the injection of PBS (50 $\mu \mathrm{L})$ GAI, GA3 and GA7 $(2 \mathrm{mg} / \mathrm{mL}, 50 \mu \mathrm{L})$; (B) Heat curves of tumors upon laser irradiation as a function of irradiation time. 
A

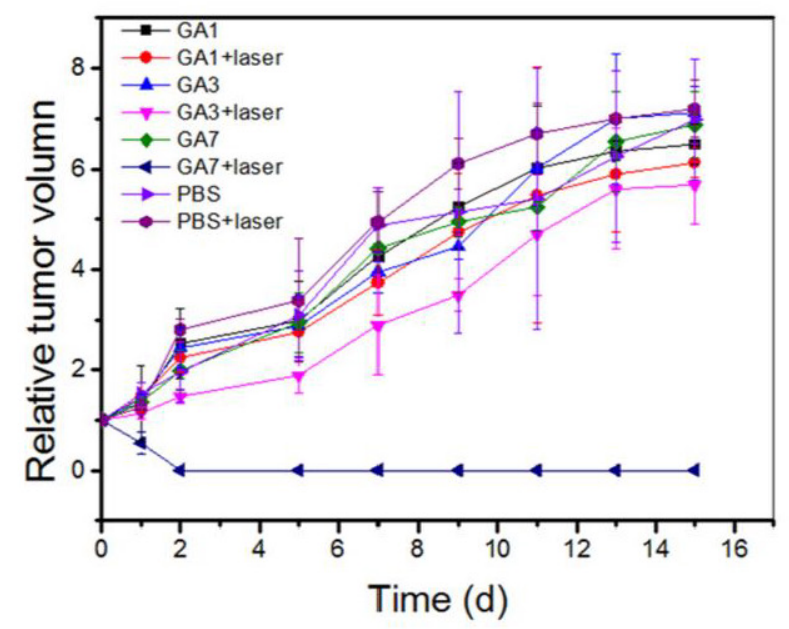

B
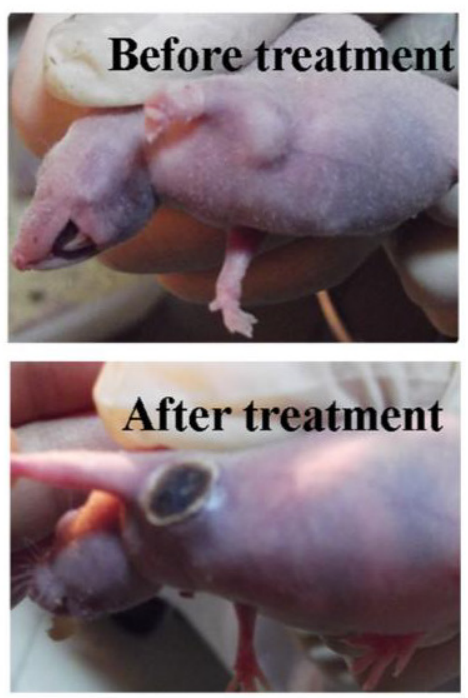

C
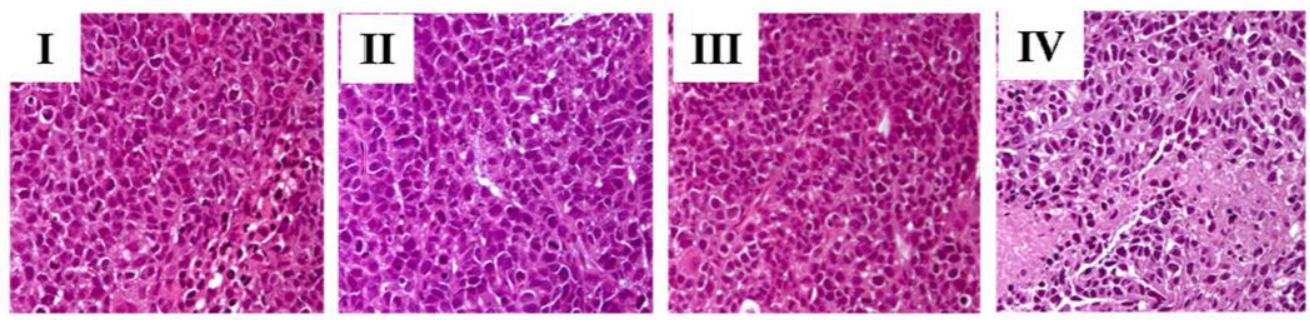

Figure 8. (A) Tumor growth curves of different groups of MCF-7 tumor-bearing mice after treatment. Tumor volumes were normalized to their initial sizes. Error bars represent the standard deviation of 3 mice per group;. (B) Photographs of MCF-7 tumor-bearing mice before and after treatment with GA7 at 808nm laser irradiation;. (C) Hematoxylin and eosin staining of tumor sections collected from different groups of mice after laser irradiation. (I) PBS, (II) GV7, (III) laser, (IV) GV7+laser.

Moreover, histochemical study of the major organs harvested from mice treated with GAs was conducted. From the H\&E results (Figure 9), no detectable lesion was observed for mice after treatment with GA7 for two weeks. These results collectively suggested that GAs possess no significant toxic to mice in vivo. However, all these experiments above were just preliminary prove to the biosafety of the GA7, more efforts were still required to systematically test the metabolic clearance rate and potential long-term toxicity of GAs in animals.

\section{CT imaging in vivo}

X-ray computed tomography (CT) was one of the most useful diagnostic tools for detecting tumor [46]. Gold nanoparticles are biocompatible and nontoxic materials with a higher X-ray absorption coefficient $\left(5.16 \mathrm{~cm}^{2} / \mathrm{g}\right.$, at $\left.100 \mathrm{keV}\right)$ [47], which makes it a potential CT contrast agent in vivo. In our experiment the GAs was intratumorally injected in tumor, the gold concentration in tumor region is high enough to distinguished tumor on the gold-enhanced CT image with good contrast. According to previous study, the region which was rich in gold nanomaterials would display an enhanced positive-contrast [48]. Before injection of GA7, the Hounsfield Units (HU) value of tumor region was 16 which was difficult to identify from surrounding tissues (HU=17). After injection of GA7 $(2 \mathrm{mg} / \mathrm{mL}, 50 \mu \mathrm{L})$, the HU value of tumor region could reach as high as 104 which was markedly higher than the $\mathrm{HU}$ value of surrounding tissues. Figure 10B showed a good contrast enhancement between the tumor and the surrounding normal tissue after injection of GA7, compared with the pre-enhanced CT image (Figure 10A), which was difficult to identify the tumor. These results indicated that the synthesized GA7 was effective for CT imaging in vivo. Moreover, GA7 also had a good effect of PTT in addition to CT signal enhancement, which could make it a potential agent for simultaneous CT imaging and PTT. 


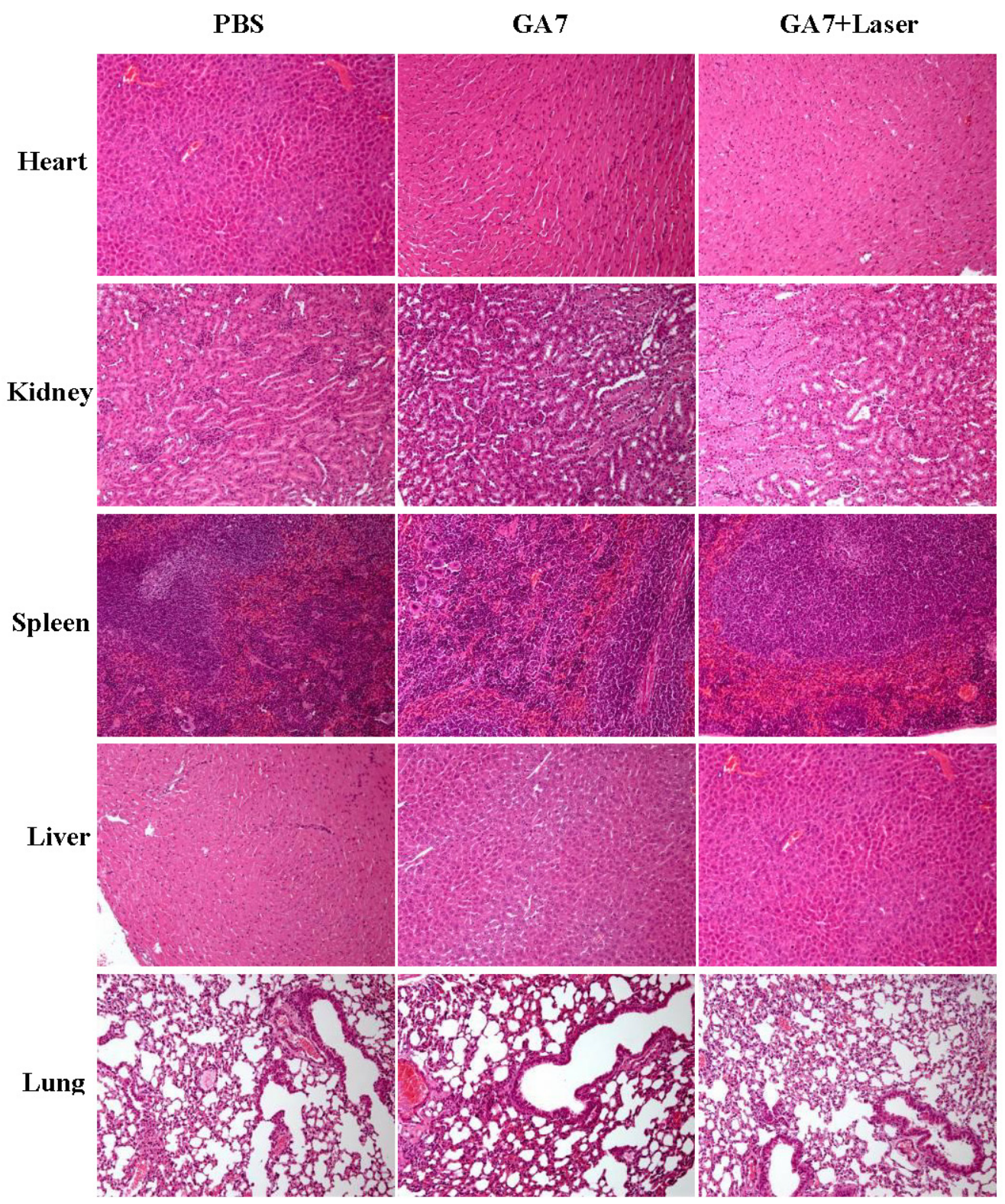

Figure 9. Hematoxylin and eosin staining of tumor sections collected from different groups of mice after laser irradiation.
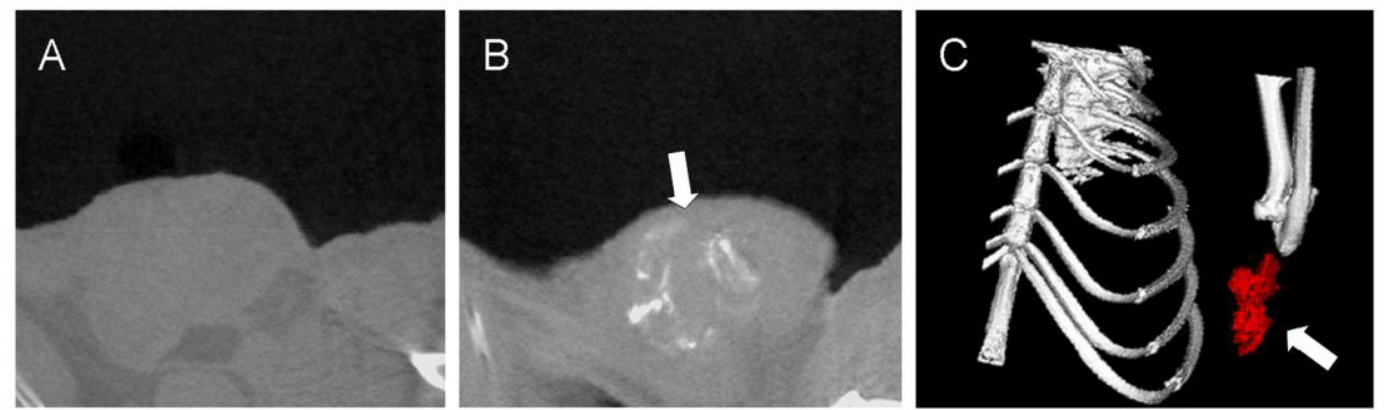

Figure 10. In vivo CT images of tumor tissues before (A) and after the injection of GA7 (B); Three-dimensional in vivo CT image of tumor tissues after the injection of GA7 (C). Arrows indicate the location of tumor.

\section{Conclusion}

In summary, we have presented a versatile method to produce ester-containing ATRP polymers with thiol group terminated, and biodegradable PCL-SH and $\mathrm{PMEO}_{2} \mathrm{MA}-\mathrm{SH}$ grafted AuNPs were obtained. By varying the ratio of these mixed polymer brush, a series of amphiphilic nanocrystals could be 
obtained. Increasing the hydrophobic/hydrophilic ratio from 1:1 to 7:1, different assembly structures from normal monolayer vesicle to LCM could be obtained. Owe to the strictly packed structure of LCM, the LSPR peaks of AuNPs could be tuned to NIR region, which made the GA7 have outstanding photothermal conversion ability and high $\mathrm{X}$-ray absorption. The optimum GAs developed in this investigation showed a commendable effect of tumor ablating and CT imaging, and exhibiting negligible toxicity to cells or animals with a good biodegradability after treatment. This GAs could be the potential candidate theranostic reagent for clinical PTT and CT imaging. Furthermore, the firstly reported LCM gold nanostructures opens new possibilities for assembling ultra small AuNPs into strong NIR absorption nanostructure for biomedical applications.

\section{Supplementary Material}

Scheme S1, Fig.S1 - S7.

http://www.thno.org/v04p0904s1.pdf

\section{Acknowledgements}

This work was financially supported by the National Natural Science Foundation of China (Grants NO. $21304099,51203162,51103159,51373177)$, the National High Technology Research and Development Program (Grants NO. 2014AA020708, 2012AA022703, and 2012AA020804), Instrument Developing Project of the Chinese Academy of Sciences (Grant No. YZ201253, and YZ201313), Open Funding Project of the National Key Laboratory of Biochemical Engineering (Grant NO. Y22504A169), "Strategic Priority Research Program" of the Chinese Academy of Sciences, Grant No. XDA09030301-3.

\section{Competing Interests}

The authors have declared that no competing interest exists.

\section{References}

1. El-Sayed IH, Huang X, El-Sayed MA. Selective laser photo-thermal therapy of epithelial carcinoma using anti-EGFR antibody conjugated gold nanoparticles. Cancer Lett. 2006; 239: 129-35.

2. Huang X, El-Sayed IH, Qian W, El-Sayed MA. Cancer cell imaging and photothermal therapy in the near-infrared region by using gold nanorods. J Am Chem Soc. 2006; 128: 2115-20.

3. Yang K, Zhang S, Zhang G, Sun X, Lee S-T, Liu Z. Graphene in mice: ultrahigh in vivo tumor uptake and efficient photothermal therapy. Nano lett. 2010; 10: 3318-23.

4. Akhavan O, Ghaderi E. Graphene nanomesh promises extremely efficient in vivo photothermal therapy. Small. 2013; 9: 3593-601.

5. Hribar KC, Lee MH, Lee D, Burdick JA. Enhanced Release of Small Molecules from Near-Infrared Light Responsive Polymer- Nanorod Composites. ACS Nano. 2011; 5: 2948-56.

6. Shan G, Weissleder R, Hilderbrand SA. Upconverting Organic Dye Doped Core-Shell Nano-Composites for Dual-Modality NIR Imaging and Photo-Thermal Therapy. Theranostics. 2012; 3: 267-74.

7. Hu J, Zhu X, Li H, Zhao Z, Chi X, Huang G, et al. Theranostic Au Cubic Nano-aggregates as Potential Photoacoustic Contrast and Photothermal Therapeutic Agents. Theranostics. 2014; 4: 534-45.
8. Kim J, Park S, Lee JE, Jin SM, Lee JH, Lee IS, et al. Designed fabrication of multifunctional magnetic gold nanoshells and their application to magnetic resonance imaging and photothermal therapy. Angew Chem Int Ed. 2006; 118: 7918-22.

9. Chen J, Wang D, Xi J, Au L, Siekkinen A, Warsen A, et al. Immuno gold nanocages with tailored optical properties for targeted photothermal destruction of cancer cells. Nano Lett. 2007; 7: 1318-22.

10. Huang P, Pandoli O, Wang X, Wang Z, Li Z, Zhang C, et al. Chiral guanosine 5'-monophosphate-capped gold nanoflowers: controllable synthesis, characterization, surface-enhanced Raman scattering activity, cellular imaging and photothermal therapy. Nano Research. 2012; 5: 630-9.

11. Zhang Z, Wang J, Chen C. Gold nanorods based platforms for light-mediated theranostics. Theranostics. 2012; 3: 223-38.

12. Chen H, Zhang X, Dai S, Ma Y, Cui S, Achilefu S, et al. Multifunctional gold nanostar conjugates for tumor imaging and combined photothermal and chemo-therapy. Theranostics. 2013; 3: 633-49.

13. Lin A, Hirsch L, Lee M-H, Barton J, Halas N, West J, et al. Nanoshell-enabled photonics-based imaging and therapy of cancer. Technology in cancer research \& treatment. 2004; 3: 33-40

14. Ke H, Wang J, Tong S, Jin Y, Wang S, Qu E, et al. Gold Nanoshelled Liquid Perfluorocarbon Magnetic Nanocapsules: a Nanotheranostic Platform for Bimodal Ultrasound/Magnetic Resonance Imaging Guided Photothermal Tumor Ablation. Theranostics. 2014; 4: 12-23.

15. O'Neal DP, Hirsch LR, Halas NJ, Payne JD, West JL. Photo-thermal tumor ablation in mice using near infrared-absorbing nanoparticles. Cancer Lett. 2004; 209: 171-6.

16. Kim D, Park S, Lee JH, Jeong YY, Jon S. Antibiofouling polymer-coated gold nanoparticles as a contrast agent for in vivo X-ray computed tomography imaging. J Am Chem Soc. 2007; 129: 7661-5.

17. Alric C, Taleb J, Duc GL, Mandon C, Billotey C, Meur-Herland AL, et al. Gadolinium chelate coated gold nanoparticles as contrast agents for both $\mathrm{X}$-ray computed tomography and magnetic resonance imaging. J Am Chem Soc. 2008; 130: 5908-15.

18. Von Maltzahn G, Park J-H, Agrawal A, Bandaru NK, Das SK, Sailor MJ, et al. Computationally guided photothermal tumor therapy using long-circulating gold nanorod antennas. Cancer Research. 2009; 69: 3892-900.

19. Bardhan R, Lal S, Joshi A, Halas NJ. Theranostic nanoshells: from probe design to imaging and treatment of cancer. Accounts of chemical research. 2011;44: 936-46.

20. Jain PK, Lee KS, El-Sayed IH, El-Sayed MA. Calculated absorption and scattering properties of gold nanoparticles of different size, shape, and composition: applications in biological imaging and biomedicine. The Journal of Physical Chemistry B. 2006; 110: 7238-48.

21. He L, Musick MD, Nicewarner SR, SaLinas FG, Benkovic SJ, Natan MJ, et al. Colloidal Au-enhanced surface plasmon resonance for ultrasensitive detection of DNA hybridization. J Am Chem Soc. 2000; 122: 9071-7.

22. Cheng L, Song J, Yin J, Duan H. Self-assembled plasmonic dimers of amphiphilic gold nanocrystals. The Journal of Physical Chemistry Letters. 2011; 2: 2258-62.

23. Maye MM, Chun SC, Han L, Rabinovich D, Zhong C-J. Novel spherical assembly of gold nanoparticles mediated by a tetradentate thioether. J Am Chem Soc. 2002; 124: 4958-9.

24. Maye MM, Luo J, Lim I-IS, Han L, Kariuki NN, Rabinovich D, et al. Size-controlled assembly of gold nanoparticles induced by a tridentate thioether ligand. J Am Chem Soc. 2003; 125: 9906-7.

25. Huang P, Lin J, Li W, Rong P, Wang Z, Wang S, et al. Biodegradable Gold Nanovesicles with an Ultrastrong Plasmonic Coupling Effect for Photoacoustic Imaging and Photothermal Therapy. Angew Chem Int Ed. 2013; 125: 14208-14.

26. Lin J, Wang S, Huang P, Wang Z, Chen S, Niu G, et al. Photosensitizer-loaded gold vesicles with strong plasmonic coupling effect for imaging-guided photothermal/photodynamic therapy. ACS Nano. 2013; 7: 5320-9.

27. He J, Huang X, Li Y-C, Liu Y, Babu T, Aronova MA, et al. Self-assembly of amphiphilic plasmonic micelle-like nanoparticles in selective solvents. J Am Chem Soc. 2013; 135: 7974-84.

28. Song J, Cheng L, Liu A, Yin J, Kuang M, Duan H. Plasmonic vesicles of amphiphilic gold nanocrystals: self-assembly and external-stimuli-triggered destruction. J Am Chem Soc. 2011; 133: 10760-3.

29. Ghosh SK, Pal T. Interparticle coupling effect on the surface plasmon resonance of gold nanoparticles: from theory to applications. Chemical Reviews. 2007; 107: 4797-862.

30. Cheng JY, Mayes AM, Ross CA. Nanostructure engineering by templated self-assembly of block copolymers. Nature materials. 2004; 3: 823-8.

31. Rösler A, Vandermeulen GW, Klok H-A. Advanced drug delivery devices via self-assembly of amphiphilic block copolymers. Advanced drug delivery reviews. 2012; 64: 270-9.

32. Zhang L, Eisenberg A. Multiple morphologies and characteristics of "crew-cut" micelle-like aggregates of polystyrene-b-poly (acrylic acid) diblock copolymers in aqueous solutions. I Am Chem Soc. 1996; 118: 3168-81.

33. Alexandridis P, Lindman B. Amphiphilic block copolymers: self-assembly and applications. Elsevier. 2000.

34. Lin $\mathrm{S}$, Zhu $\mathrm{W}, \mathrm{He} X$, Xing $\mathrm{Y}$, Liang $\mathrm{L}$, Chen $\mathrm{T}$, et al. Multicompartmental Hollow Micelles Formed by Linear ABC Triblock Copolymers in Aqueous Medium. The Journal of Physical Chemistry B. 2013; 117: 2586-93. 
35. Cohn D, Hotovely Salomon A. Designing biodegradable multiblock PCL/PLA thermoplastic elastomers. Biomaterials. 2005; 26: 2297-305.

36. Liras M, García O, Quijada-Garrido I, París R. Transformation of the Bromine End Group into Thiol in (Meth)acrylic Polymers Synthesized by Atom Transfer Radical Polymerization. Macromolecules. 2011; 44: 1335-9.

37. Yang J, Zhang P, Tang L, Sun P, Liu W, Sun P, et al. Temperature-tuned DNA condensation and gene transfection by PEI-g-(PMEO2MA-b-PHEMA) copolymer-based nonviral vectors. Biomaterials. 2010; 31: 144-55.

38. Tang L, Yang Y, Bai T, Liu W. Robust MeO2MA/vinyl-4,6-diamino-1,3,5-triazine copolymer hydrogels-mediated reverse gene transfection and thermo-induced cell detachment. Biomaterials. 2011; 32: 1943-9.

39. Wu W, Shen J, Banerjee P, Zhou S. Core-shell hybrid nanogels for integration of optical temperature-sensing, targeted tumor cell imaging, and combined chemo-photothermal treatment. Biomaterials. 2010; 31: 7555-66.

40. Lutz J-F, Akdemir Ö, Hoth A. Point by Point Comparison of Two Thermosensitive Polymers Exhibiting a Similar LCST: Is the Age of Poly(NIPAM) Over? J Am Chem Soc. 2006; 128: 13046-7.

41. Wiltshire JT, Qiao GG. Synthesis of Core Cross-Linked Star Polymers with Adjustable Coronal Properties. Macromolecules. 2007; 41: 623-31.

42. $\mathrm{Hu}$ J, Wu T, Zhang G, Liu S. Efficient Synthesis of Single Gold Nanoparticle Hybrid Amphiphilic Triblock Copolymers and Their Controlled Self-Assembly. J Am Chem Soc. 2012; 134: 7624-7.

43. Hickey RJ, Haynes AS, Kikkawa JM, Park SJ. Controlling the self-assembly structure of magnetic nanoparticles and amphiphilic block-copolymers: from micelles to vesicles. J Am Chem Soc. 2011; 133: 1517-25.

44. Song J, Fang Z, Wang C, Zhou J, Duan B, Pu L, et al. Photolabile plasmonic vesicles assembled from amphiphilic gold nanoparticles for remote-controlled traceable drug delivery. Nanoscale. 2013; 5: 5816-24.

45. Peng C-L, Shih Y-H, Lee P-C, Hsieh TM-H, Luo T-Y, Shieh M-J. Multimodal Image-Guided Photothermal Therapy Mediated by 188Re-Labeled Micelles Containing a Cyanine-Type Photosensitizer. ACS Nano. 2011; 5: 5594-607.

46. Wildenschild D, Vaz C, Rivers M, Rikard D, Christensen B. Using X-ray computed tomography in hydrology: systems, resolutions, and limitations. Journal of Hydrology. 2002; 267: 285-97.

47. Hainfeld JF, Slatkin DN, Focella TM, Smilowitz HM. Gold nanoparticles: a new X-ray contrast agent. The British Journal of Radiology. 2006; 79: 248-53.

48. Huang P, Bao L, Zhang C, Lin J, Luo T, Yang D, et al. Folic acid-conjugated silica-modified gold nanorods for X-ray/CT imaging-guided dual-mode radiation and photo-thermal therapy. Biomaterials. 2011;32: 9796-809. 